\title{
Experimental Investigation of Inserted Twisted Tape Pitch Effect in Evacuated Solar Water Heater
}

\author{
Hitendra Damarlal Chaudhary ${ }^{1}$, Dr Sadanand A Namjoshi ${ }^{2}$ \\ ${ }^{1}$ Research Scholar, \\ Madhav University, Pindwara (Sirohi), Rajasthan, India
}

\begin{abstract}
Although productivity and manufacturing may always be met simply through the use of energy, the availability of energy is crucial in economic activity. These days, limited energy is needed for any country 's economic growth; however, so because large number of energy is still retrieved from fossil fuels, nations with insufficient quantities of such fossil fuels confront various problems of unemployment; however, the remedy to this energy crisis can be found in alternate solution energy such as solar, wind and biomass; even so, alternative sources such as solar, wind and biomass are not yet available; even so, alternate solution for energy such as solar, wind, and biomass are not yet available This research aims to determine how the height of twisted insertion tape influences the performance of evacuated tube solar water heaters.
\end{abstract}

Keywords: Solar Water Heater, Evacuated Tube, Twisted Tape, Solar Energy

\section{Introduction}

Radiation from solar for solar thermal power is perhaps the most potential of a unconventional energy sources, based on present industrial economic development and environmental implications. Parabolic trough concentrators are used in the majority of commercially accessible solar power systems. Solar energy is indeed an exhaustible form of energy that have the potential to meet a larger fraction of all nations' future power needs while causing the least amount of environmental damage. Solar energy for solar thermal plants is perhaps the most potential of unconventional energy sources, based on current industrial economic development and environmental implications. Energy from sun has been suggested is a possible alternative source of energy for the use in future. Usage of thermal energy from sun is critical for the protection of the environment and traditional energy savings. Even as trends in the United States and Japan illustrate, millions of families throughout the world are anticipated to use solar energy in the next years. Cooking/heating, drying/timber seasoning, distilling, electricity/power generating, cooling, and refrigeration all utilise this energy. Solar cookers, Solar flat plate cookers, Concentrating collectables, Solar water heaters (household and commercial), Solar hot air structures, Solar Dryers, Solar firewood kilns, solar stills, Photovoltaic solar systems, Solar pond, Power Tower, Conditioning systems, Solar collectors, combined to absorption, Cooling systems are just a few of the gadgets and other devices.

All the sunlight and the major of the warm which we get on Earth is due to solar radiation. That's a lot of untapped potential energy. Solar thermal collectors use absorption and conduction to capture the sun's heat and use it to heat water. It could be used to cook meals with reflectors and to warmth rooms with strategically windows which are placed. Even photons (light) which we get from the sun rays could be converted into electricity using photovoltaic cells. The sun by farer is the biggest and the most accessible renewable energy source on the planet. O. P. Shukla et. al [1] used CFD to evaluate the performance of a solar type water heater using a flat - plate type solar collector and evacuating tubes with fin tubes. For heating, a flow rate of around 0.2 litres per minute is ideal. The heaters should be used intermittently to heat a batch of water for 15 to 20 minutes, just until the efficiency falls below 50\%, and then fresh water should be run through it. Anand Patel et. al [2, 3, 4] published experimented results on a solar type water heater that used helical \& serpentine shape tubes, and also a solar type water heater that used phase change material (PCM). Y. Taheri, Behrooz et. al [5] developed a new approach of solar water heater utilising black coated sand, and the collector average daily efficiencies reached higher than $70 \%$ in all experiments. Hussain AlMadani [6] performed an experimental study on a cylinder - shaped solar type water heater and measured its 
efficiency. The highest value discovered during the trial was 41.8 percent. This illustrates the system's capability to turn solar energy as heat capable of heating water. From an economic analysis, the cylinder shaped solar type water heater is much more cost effective than the flat plate collector. Chii-Dong Ho et. al [7] evaluated both theoretically and empirically the collector performance of a recyclic flat plate type solar water heating system to rectangular conduit cross - section. Increase in the rate of convective heat transfer is what the recycle-effect concept entails. The effect of flowing conduit aspect ratio, inbound solar radiation, inlet temperature of water, number of conduit pairs, recycling ratio, and water flowrate on collector efficiency is investigated. C.C. Chien et. al [8] experimented a 2 phase thermo syphon solar type water heater both practically \& theoretically. The efficiency of this revolutionary solar type water heater is investigated experimentally at various solar radiation intensity and tilt angles. According to the findings, the system's best charge efficiency is 82 percent, which is better than that of traditional solar water heaters. Behrooz M. Ziapour et. al [9] investigated whether an integrating collector-storage solar water heater (ICSSWH) is less expensive than existing solar water heaters. Numerical simulation and validation of an effective ICSSWH system are performed. The greater standard of stratification in the storage unit was used to model the baffle plate kind of the two trapezoid ICSSWH systems. The numerical programed was run on both cloudy and clear days. The outcomes of the current technique were then compared to other simulation and experimental values.

\section{Experimentation}

Firstly, three tubes which are evacuated are constructed with $20 \mathrm{~mm}$ ID and $40 \mathrm{~mm}$ OD glassware and a length of $1 \mathrm{~m}$ are inserted with twisted tapes on the right hand side twist, while another set of the same dimensions is placed with twisted tape on the left hand side twist. Those three tubes are attached to the water tank made of mild steel with a black finish and measuring 6" in diameter and 15" in length, from which hot and cold water is redistributed in the system using the convective current concept. The thermocouples of the ' $\mathrm{K}$ ' type can be used to calculate the temperature of water at the inlet and output and also the temperature of the body. To measure the mass flow rate of water, a measuring flask with a volume of $1000 \mathrm{ml}$ is employed. In addition, left and right hand pitch twisted tapes were alternately put in $18 \mathrm{~mm}$ ID and $20 \mathrm{~mm}$ ID evacuated tubes, with 30 minute intervals between experiments.

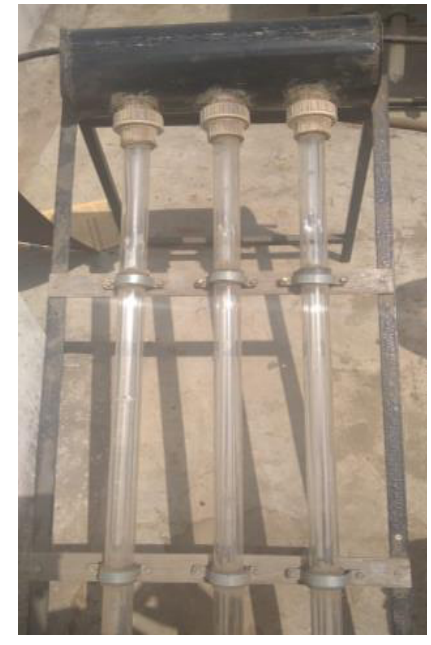

(a) Experimental Set Up



(b) Evacuated Tube with Twisted Tape

Figure 1

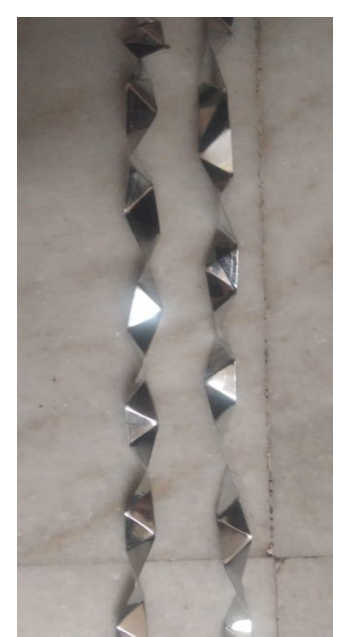

(c) Short Pitch and Long Pitch twisted Tape 
A: Short Pitch Twisted Tape in Evacuated Tube, B: Long Pitch Twisted Tape in Evacuated Tube

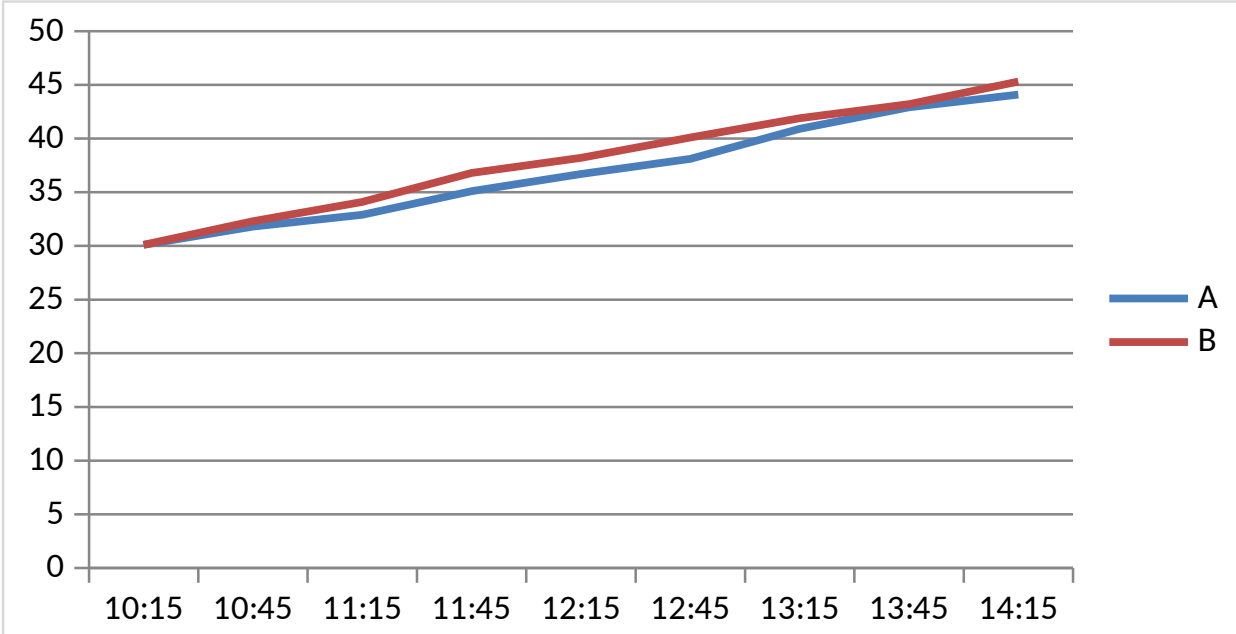

Figure 2: Temperature Variation for Low Flow Rate

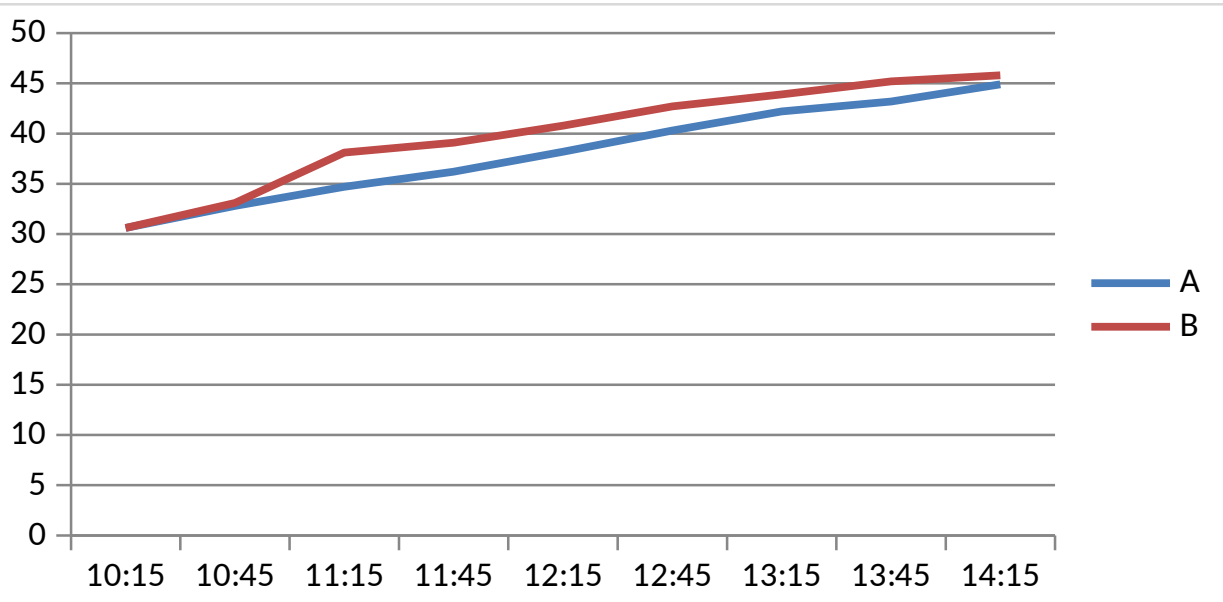

Figure 3: Temperature Variation for Medium Flow Rate

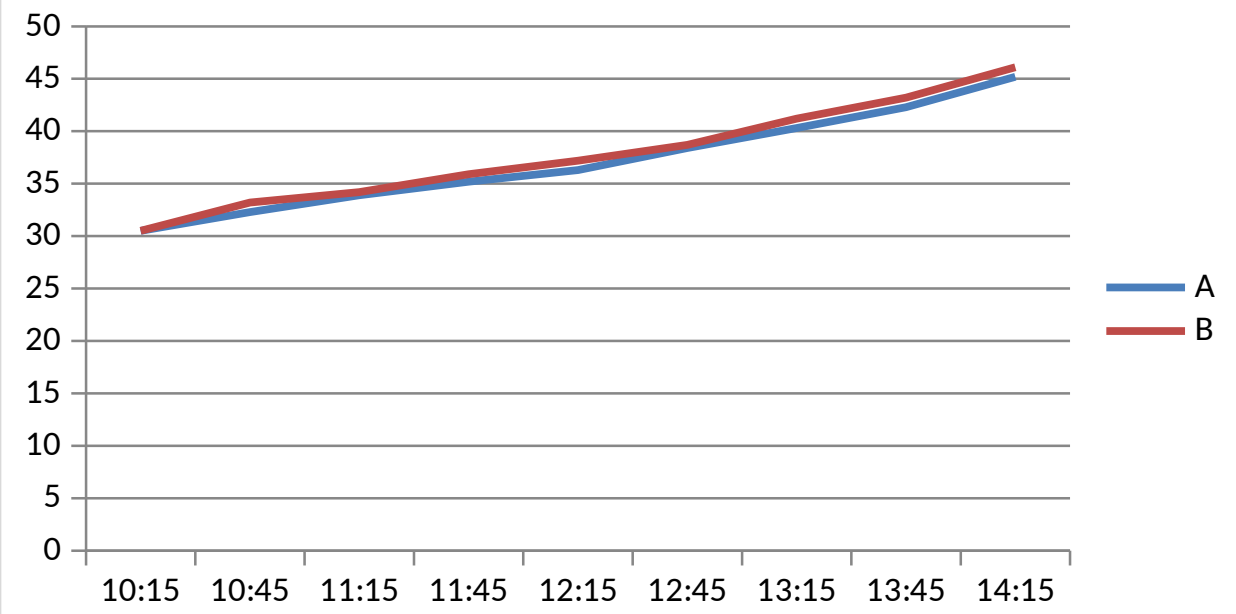

Figure 4: Temperature Variation for High Flow Rate

Table 1: Mass Flow Rate of Water for Solar Water Heater

\begin{tabular}{|c|c|c|}
\hline Flow & Time Required to Fill $\mathbf{1 0 0 0}$ ml Flask (s) & Flow Rate (lps) \\
\hline Low & 735 & 0.00136 \\
\hline Medium & 695 & 0.00144 \\
\hline
\end{tabular}




\begin{tabular}{|l|l|l|}
\hline High & 617 & 0.00162 \\
\hline
\end{tabular}

\section{Conclusions}

1. From observations it is clear that flow rate is the influencing factor; and at high flow rate, the gain in temperature is low due to less retention time for water.

2. Most interesting observation in the present work is - as in the case of short pitch twisted tape, more turbulence can be obtained compared to the long pitch twisted tape, which leads to more increment in water temperature.

3. The major conclusion of present work is that by inserting twisted tape with short pitch, we can obtain the thermal performance of solar water which is better than others.

\section{References}

[1] O.P Shukla, Deepanjal Kumar Gupta, Performance Evaluation of Solar Water Heater by Using Flat Plate Collector and Evacuated Tubes with Fin Tube Using CFD, October 2018 IJIRT Volume 5 Issue 5 ISSN: 2349-6002

[2] Anand Patel and Sadanand Namjoshi, "Phase change material based solar water heater," International Journal of Engineering Science Invention., vol. 5, no. 8, August 2016. PP. 31-34.

[3] Patel A, Parmar H, Namjoshi S 2016 Comparative thermal performance studies of serpentine tube solar water heater with straight tube solar water heater. IOSR Journal of Mechanical and Civil Engineering (IOSR-JMCE) 13 79-83.

[4] Anand Patel, Divyesh Patel, Sadananad Namjoshi Thermal Performance Analysis of Helical Solar Water Heater, International Journal of Innovative Technology and Exploring Engineering (IJITEE) ISSN: 2278-3075, Volume-5 Issue-3, August 2015. PP 67-69.

[5] Y. Taheri, Behrooz M.Ziapour,K.Alimardani, Study of an efficient compact solar water heater, Energy Conversion and Management 70 (2013) 187-193

[6] Hussain Al-Madani, The performance of a cylindrical solar water heater, Renewable Energy 31 (2006) $1751-1763$

[7] Chii-Dong Ho, Tsung-Ching Chen, Cheng-Jung Tsai, Experimental and theoretical studies of recyclic flat-plate solar water heaters equipped with rectangle conduits, Renewable Energy 35 (2010) 22792287

[8] C.C. Chien, C.K. Kung, C.C. Chang, W.S. Lee, C.S. Jwo, S.L. Chen, Theoretical and experimental investigations of a two-phase thermosyphon solar, Energy 36 (2011) 415e423 water heater

[9] Behrooz M. Ziapour, Vahid Palideh, Ali Mohammadnia, Study of an improved integrated collectorstorage solar water heater combined with the photovoltaic cells, Energy Conversion and Management 86 (2014) 587-594 